\title{
Songs and Spiritual Life: A Phenomenological Study
}

\author{
Anne Lou M. Hendriks \\ Universitas Advent Indonesia
}

\begin{abstract}
The influence of songs in English language learning is substantiated in many studies. Songs are considered to be influential not only to learners' language skills but also to their character. However, though the aforementioned relationships are widely studied, little is known about the relationship between song and its role to learners' spiritual life. This phenomenological study among 28 participants revealed the kind of songs that can contribute to the spiritual life of the learners. It highlights pedagogical insights of an instructional strategy for integrating faith into learning.
\end{abstract}

Keywords: songs, spiritual life, phenomenological study, Indonesia 